\title{
Distal Radial Artery Access: The Future of Cardiovascular Intervention
}

\author{
Zaid Nairoukh $^{1}$, Saira Jahangir ${ }^{2}$, Dennis Adjepong ${ }^{3}$, Bilal Haider Malik ${ }^{1}$ \\ 1. Internal Medicine, California Institute of Behavioral Neurosciences and Psychology, Fairfield, USA 2. Neuroscience, \\ California Institute of Behavioral Neurosciences and Psychology, Fairfield, USA 3. Neurological Surgery, California \\ Institute of Behavioral Neurosciences and Psychology, Fairfield, USA
}

Corresponding author: Zaid Nairoukh, zaid.m.nairoukh@students.kasralainy.edu.eg

\begin{abstract}
Access sites for coronary intervention have been changing over the last several decades, from the femoral artery to the radial artery and then to the distal radial artery. Distal radial access, which was first used in 2017 and is still not recommended by the guidelines, shows a higher success rate and less complications than other sites; therefore, it might be the future for cardiovascular intervention. In this study, we reviewed almost all of the articles that are related to the distal radial access, from 2017 to present, and summarized the technique, success rate, advantages, disadvantages, and noncardiac use of this access site.
\end{abstract}

Categories: Cardiology

Keywords: distal radial artery access, distal radial artery approach, snuffbox approach, snuffbox access, cardiovascular intervention, coronary angiography, coronary intervention, coronary angioplasty

\section{Introduction And Background}

Over the last several years, many changes have occurred in the treatment of ischemic heart diseases; one of these changes is the route of arterial access for both coronary angiography and percutaneous coronary interventions.

Access changed from transfemoral to transradial approach (TRA), as it has less bleeding complications, decreased hospital mortality rate, less access site complications, and is cost-effective as compared to the transfemoral approach [1]. In 2015, the European Society of Cardiology guidelines for the management of acute coronary syndrome gave class I recommendation to use the TRA as the preferred method of access for any percutaneous coronary intervention irrespective of clinical presentation [2].

However, the use of TRA is not free of limitations; many complications have been associated with the TRA due to small diameter, such as radial artery occlusion (RAO) (The reported incidence of RAO is highly variable in the range of $2 \%-10 \%$, and a meta-analysis by Rashid showed that the RAO incidence within 24 hours was $7.7 \%$ ), radial artery spasm, radial arterial perforation, radial artery pseudoaneurysm,

Received 01/04/2020

Review began 03/02/2020 Review ended 03/05/2020 Published 03/07/2020

\section{() Copyright 2020}

Nairoukh et al. This is an open access article distributed under the terms of the Creative Commons Attribution License CC-BY 4.0., which permits unrestricted use, distribution, and reproduction in any medium, provided the original author and source are credited. arteriovenous fistula, bleeding, nerve damage, and complex regional pain syndrome [3,4].

Recently, a new approach was proposed to overcome these limitations and also to give the advantage over the transfemoral approach; this was a "distal transradial approach (dTRA) (snuffbox approach)". The first publication was proposed in 2017 by Kiemeneij, and after that, a large number of studies have evaluated the safety and feasibility of this new approach [5].

In this study, we review the most related and recent articles to know more about the dTRA through rapid revision of radial artery anatomy. We then discuss preparation and technique of this approach and how proper preparation can improve success rate, and compare advantages and disadvantages of this approach over the old approach. We also touch on other noncardiac interventions that might be done by this approach. Finally, we attempt to confirm if this approach could be the future guideline for cardiovascular intervention.

\section{Review}

\section{Anatomy}

The anatomical snuffbox is defined as a triangular depression on the dorsum of the hand at the base of the thumb; it is bordered by the abductor pollicis longus and extensor pollicis brevis laterally and the extensor pollicis longus medially. The floor is formed by the scaphoid and trapezium carpal bones. The contents of the anatomical snuffbox include the distal radial artery (DRA), cephalic vein, and superficial branches of the radial nerve.

There are two sites at which the radial pulse can be found: in the anatomic snuffbox and the first intermetacarpal space; these two sites represent alternative puncture points for TRA [5]. As the radial artery has reached the anatomic snuffbox, it has already given rise to some branches that, in case of vessel 
occlusion, could avoid flow interruption. Flow interruption appears to play a significant role in artery occlusion. Indeed, in a retrospective series, the absence of blood flow during the hemostasis process significantly increased the risk for RAO [6]. On this background, dTRA could maintain forearm radial artery patency during hemostatic compression or in case of occlusion at the puncture site [7].

\section{Diameter}

It is essential to know that DRA diameter is $80 \%$ less than the proximal, and this may affect suitable French sheath that can be used and it varies according to sex, race, and other factors. The diameter of the DRA in females tends to be smaller than that in males. Some studies show that hypertensive patients had larger radial artery diameter than normal. Other studies show that the diameter of DRA positively correlated with both body weight and basal metabolic index. Ulnar arteries were slightly larger than radial arteries and may be used as an alternative to DRA [8-10].

Here are some examples of means of internal diameter of radial artery from different areas: in Korea (2.57 \pm $0.50 \mathrm{~mm})$, in India $(2.325 \pm 0.4 \mathrm{~mm})$, in Japan $(2.6 \pm 0.5 \mathrm{~mm})$, in Pakistan $(2.25 \pm 0.4 \mathrm{~mm})$, in Singapore $(2.45$ $\pm 0.54 \mathrm{~mm})$, in Turkey $(2.05 \pm 0.34 \mathrm{~mm})[8-13]$.

\section{Ultrasound guidance}

A blind puncture increases the risk of tendon damage. And at the same time, the double-wall technique can irritate the underlying periosteum and increase the risk of hematoma formation. The utilization of the ultrasound (US) allows identification of anatomical landmarks, and enables accurate vessel access, especially in impalpable DRA. The probe can be used to perform a compressibility test to confirm that the target vessel corresponds to the radial artery rather than the cephalic vein. Accurate scanning can identify the superficial branch of the radial nerve, thus avoiding potential injury. A further benefit of US guidance is that the operator can measure the vessel size before puncturing. The outer diameters of 5 French, 6 French, and 7 French introducer sheaths are usually $2.3,2.6$, and $2.8 \mathrm{~mm}$ respectively, and it can help to determine whether the radial artery can accommodate the required procedural sheath and hardware, and to choose a smaller diameter sheath in order to reduce the risk of vascular injury, unnecessary patient pain, and RAO $[10,14]$.

\section{Technique}

The left upper arm is placed comfortably on a cushion on the left side of the patient. The left hand is bent over towards the patient's right groin. After disinfection, the patient is covered with a sterile drape. To bring the DRA to the surface of the radial fossa, the patient grasps his thumb under the other four fingers. After subcutaneous injection of 3-5 cc xylocaine, the artery is punctured, preferably with a 21 gauge open needle, under an angle of 30-45 degrees and from lateral to medial. The needle directed to the point of most forceful pulse, proximal in the anatomical snuffbox. A through-and-through puncture is not recommended because the contact of the needle to the periosteum of scaphoid and trapezium bones can be painful. After successful puncture, a flexible, soft, J-shaped 0.21" metallic wire was inserted. After administration of a spasmolytic cocktail (200 mcg of nitroglycerine and $5 \mathrm{mg}$ of verapamil) and a weight-adjusted dose of heparin, the operator can take up a position at the level of the patient's knees to manipulate the 0.35 " wire, the catheters, and the intracoronary devices. After the procedure, the sheath is pulled out for $3 \mathrm{~cm}$, after which a SafeGuard (Merit Medical Systems,South Jordan, UT) hemostasis band is placed over the puncture site. At inflation of 3 $\mathrm{mL}$ of air into the air compartment, the sheath is pulled out completely, followed by an extra injection of 2 $\mathrm{mL}$ of air. This band is left in situ for two or maximally three hours, after which deflation of air is started and completed within half an hour. Alternatively, a small pile of gauze is placed over the puncture site during sheath removal, followed by the application of a semi-elastic bandage, which is left in situ for two to three hours [5].

\section{Success rate}

Multiple studies have been publishing over the last three years, and most of them have a high success rate (approximately 90\%). Table 1 shows the success rate and complications of distal radial artery access in approximately all studies after Kiemeneij. 


\section{Cureus}

\begin{tabular}{|c|c|c|c|c|c|}
\hline Year & Author & $\begin{array}{l}\text { Country of the } \\
\text { study }\end{array}$ & $\begin{array}{l}\text { Number of patients } \\
\text { (PCI) }\end{array}$ & $\begin{array}{l}\text { Success } \\
\text { rate, } \%\end{array}$ & Complications, \% \\
\hline $\begin{array}{l}\text { May } \\
2017\end{array}$ & Kiemeneij [5] & Netherlands & $70(25)$ & 89 & dRAO: $1.5 \%$ \\
\hline $\begin{array}{l}\text { Jul } \\
2017\end{array}$ & Amin et al. [15] & Bangladesh & 50 & 98 & No complications observed \\
\hline $\begin{array}{l}\text { Jan } \\
2018\end{array}$ & $\begin{array}{l}\text { Roghani-Dehkordi et } \\
\text { al. [16] }\end{array}$ & Iran & 235 & 94 & No complications observed \\
\hline $\begin{array}{l}\text { Mar } \\
2018\end{array}$ & Al-Azizi and Lotfi [17] & US & $22(7)$ & 100 & No complications observed \\
\hline $\begin{array}{l}\text { Mar } \\
2018\end{array}$ & Valsecchi et al. [18] & Italy & $52(25)$ & 90 & pRAO: $4 \%$, artery spasm: $2 \%$ \\
\hline $\begin{array}{l}\text { Mar } \\
2018\end{array}$ & Soydan and Akin [19] & Turkey & $54(20)$ & 96.3 & Artery spasm: $3.7 \%$ \\
\hline $\begin{array}{l}\text { Aug } \\
2018\end{array}$ & Coughlan et al. [20] & Ireland & 47 & 100 & No complications observed \\
\hline $\begin{array}{l}\text { Aug } \\
2018\end{array}$ & Kim et al. [21] & Korea & $150(42)$ & 88 & Hematoma: $4.9 \%$ \\
\hline $\begin{array}{l}\text { Sep } \\
2018\end{array}$ & Koutouzis et al. [22] & Greece & 100 & 70 & No complications observed \\
\hline $\begin{array}{l}\text { Oct } \\
2018\end{array}$ & Ziakas et al. [23] & Greece & $49(8)$ & 90 & $\begin{array}{l}\text { Hematoma: } 16 \% \text {, bleeding: } 4.5 \% \text {, artery spasm: } \\
16 \% \text {, pain: } 9 \% \text {, }\end{array}$ \\
\hline $\begin{array}{l}\text { Dec } \\
2018\end{array}$ & Wretowski et al. [24] & Poland & $218(48)$ & 89.4 & No complications observed \\
\hline $\begin{array}{l}\text { Feb } \\
2019\end{array}$ & Aoi et al. [25] & US & $202(90)$ & 99.5 & $\begin{array}{l}\text { Hematoma: } 10.1 \% \text {, dRAO: } 1.0 \% \text {, arteriovenous } \\
\text { fistula: } 0.5 \%\end{array}$ \\
\hline $\begin{array}{l}\text { Mar } \\
2019\end{array}$ & Maitra et al. [26] & India & 55 & 87.3 & Hematoma $2 \%$ \\
\hline $\begin{array}{l}\text { Apr } \\
2019\end{array}$ & Norimatsu et al. [10] & Japan & $74(27)$ & 91 & o complications observed \\
\hline $\begin{array}{l}\text { May } \\
2019\end{array}$ & Gasparini et al. [27] & Italy & $41(41)$ & 82.9 & Artery spasm: 10\%, dRAO: $2.4 \%$ \\
\hline $\begin{array}{l}\text { May } \\
2019\end{array}$ & Mizuguchi et al. [28] & Japan & $228(77)$ & 99.5 & $\begin{array}{l}\text { Hematoma: } 4.4 \% \text {, pRAO: } 0.4 \% \text {, dRAO: } 3.1 \% \text {, } \\
\text { numbness: } 0.9 \%\end{array}$ \\
\hline $\begin{array}{l}\text { Jul } \\
2019\end{array}$ & Vefali et al. [13] & Turkey & $102(24)$ & 95.1 & No complications observed \\
\hline $\begin{array}{l}\text { Sep } \\
2019\end{array}$ & Lee et al. [29] & Korea & $200(86)$ & 95.5 & $\begin{array}{l}\text { Hematoma: } 7.4 \% \text {, arterial dissection: } 0.5 \% \text {, } \\
\text { numbness: } 1 \%\end{array}$ \\
\hline $\begin{array}{l}\text { Dec } \\
2019\end{array}$ & Aqel et al. [30] & Palestine & $200(17)$ & 98 & No complications observed \\
\hline
\end{tabular}

TABLE 1: Success rate and complication of distal radial artery access in cardiovascular intervention.

$\mathrm{PCl}$, percutaneous coronary intervention; $\mathrm{dRAO}$, distal radial artery obstruction; pRAO, proximal radial artery occlusion

\section{Advantage}


dTRA technique seems to have more advantages. First, the arm position during the intervention is comfortable for the patient, who does not have to expose the palmar side of the arm while flexing the upper arm towards the operator. No equipment or investments are necessary to support the patient's left arm. The operator can work as usual from the right side of the patient and does not need to bend over the patient to reach for the left radial artery. Second, there is low rate of DRA obstruction Since antegrade flow through the superficial palmar arch is still maintained, the radial artery does not thrombose in case of occlusion of the radial artery in the snuffbox. Other advantages include early hemostasis, low risk for hematoma formation, low level of pain perceived by patients, reduced risk of compartment syndrome, saving the radial artery for possible future coronary artery bypass graft, and the ability of the operator to work at a safe distance from the radiation source $[5,13,22,31]$. Finally, it might be a potential site for retrograde recanalization of RAO [32].

\section{Disadvantage}

The disadvantages of dTRA are that they are technically more demanding and time-consuming, especially in access time. The radiation time was more. The snuffbox radial artery is smaller in diameter than the radial artery, and there is a higher risk of puncture-mediated vasospasm than TRA. However, in DRA vasospasm, we can cross to multiple other accesses like distal ulnar or contralateral dTRA, proximal TRA, or transfemoral. Lastly, the short length of a typical radial catheter is a significant drawback to the snuffbox technique. Given that the snuffbox artery is $5 \mathrm{~cm}$ below the common radial entry site, these catheters may, therefore, be too short, especially in taller patients [13].

\section{Noncardiac use}

Distal radial access can also be used for interventions other than cardiac, and a study in 2017 demonstrates using this approach in 50 visceral interventions [33]. Another case series study in 2019 on 85 patients demonstrates the feasibility of this approach as diagnostic in cerebral angiography [34]. Distal radial access is used for proximal RAO even if it associated with acute coronary syndrome, based on a case reported recently [33]. The last one, which is common, is using the DRA for arteriovenous fistula in dialysis, which affords more advantages than the traditional proximal fistula $[35,36]$.

\section{Conclusions}

Distal radial access is a new site for cardiovascular interventions, and it has several advantages over the old access sites. The main advantages are less arterial obstruction and short hemostasis. The main disadvantage is the difficulty in cannulation. However, more studies, especially randomized studies and meta-analyses, are needed to be a guideline in the future.

\section{Additional Information \\ Disclosures}

Conflicts of interest: In compliance with the ICMJE uniform disclosure form, all authors declare the following: Payment/services info: All authors have declared that no financial support was received from any organization for the submitted work. Financial relationships: All authors have declared that they have no financial relationships at present or within the previous three years with any organizations that might have an interest in the submitted work. Other relationships: All authors have declared that there are no other relationships or activities that could appear to have influenced the submitted work.

\section{References}

1. Anjum I, Khan MA, Aadil M, Faraz A, Farooqui M, Hashmi A: Transradial vs. transfemoral approach in cardiac catheterization: a literature review. Cureus. 2017, 9:e1309. doi:10.7759/cureus.1309

2. Roffi M, Patrono C, Collet J-P, et al.: 2015 ESC Guidelines for the management of acute coronary syndromes in patients presenting without persistent ST-segment elevation: Task Force for the Management of Acute Coronary Syndromes in Patients Presenting without Persistent ST-Segment Elevation of the European Society of Cardiology (ESC). Eur Heart J. 2016, 37:267-315. doi: 10.1093/eurheartj/ehv320

3. Rashid M, Kwok CS ,Pancholy S, et al.: Radial artery occlusion after transradial interventions: a systematic review and meta-analysis. J Am Heart Assoc. 2016, 5:e002686. doi: 10.1161/JAHA.115.002686

4. Aoun J, Hattar L, Dgayli K, Wong W, Bhat T: Update on complications and their management during transradial cardiac catheterization. Expert Rev Cardiovasc Ther. 2019, 17:741-751. 10.1080/14779072.2019.1675510

5. Kiemeneij F: Left distal transradial access in the anatomical snuffbox for coronary angiography (ldTRA) and interventions (ldTRI). EuroIntervention. 2017, 13:851-857. 10.4244/EIJ-D-17-00079

6. Sanmartin M, Gomez M, Rumoroso JR, et al.: Interruption of blood flow during compression and radial artery occlusion after transradial catheterization. Catheter Cardiovasc Interv. 2007, 70:185-189. 10.1002/ccd.21058

7. Sgueglia GA, Di Giorgio A, Gaspardone A, Babunashvili A: Anatomic basis and physiological rationale of distal radial artery access for percutaneous coronary and endovascular procedures. JACC Cardiovasc Interv. 2018, 11:2113-2119. 10.1016/j.jcin.2018.04.045

8. Kim Y, Ahn Y, Kim MC, et al.: Gender differences in the distal radial artery diameter for the snuffbox approach. Cardiol J. 2018, 25:639-641. DOI: 10.5603/CJ.2018.0128 
9. Beniwal S, Bhargava K, Kausik SK: Size of distal radial and distal ulnar arteries in adults of southern Rajasthan and their implications for percutaneous coronary interventions. Indian Heart J. 2014, 66:506-509. 10.1016/j.ihj.2014.08.010

10. Norimatsu K, Kusumoto T, Yoshimoto K, et al.: Importance of measurement of the diameter of the distal radial artery in a distal radial approach from the anatomical snuffbox before coronary catheterization. Heart Vessels. 2019, 34:1615-1620. 10.1007/s00380-019-01404-2

11. Ashraf T, Panhwar Z, Habib S, Memon MA, Shamsi F, Arif J: Size of radial and ulnar artery in local population. J Pak Med Assoc. 2010, 60:817-819.

12. Loh YJ, Nakao M, Tan WD, Lim CH, Tan YS, Chua YL: Factors influencing radial artery size. Asian Cardiovasc Thorac Ann. 2007, 15:324-326. 10.1177/021849230701500412

13. Vefali V, Sarıçam E: The comparison of traditional radial access and novel distal radial access for cardiac catheterization. Cardiovasc Revasc Med. 2019, Epub ahead of print. 10.1016/j.carrev.2019.07.001

14. Hadjivassiliou A, Kiemeneij F, Nathan S, et al.: Ultrasound-guided access of the distal radial artery at the anatomical snuffbox for catheter-based vascular interventions: a technical guide. EuroIntervention. 2019, Epub ahead of print.

15. Amin MR, Singha C, Banerjee S, et al.: Comparison of distal transradial in the anatomical snuffbox versus conventional transradial access for coronary angiography and intervention-an experience in 100 cases. Univ Heart J. 2018, 13:40-45. https://doi.org/10.3329/uhj.v13i2.37657

16. Roghani-Dehkordi F, Hashemifard O, Sadeghi M, et al.: Distal accesses in the hand (two novel techniques) for percutaneous coronary angiography and intervention. ARYA Atheroscler. 2018, 14:95-100. 10.22122/arya.v14i2.1743

17. Al-Azizi KM, Lotfi AS: The distal left radial artery access for coronary angiography and intervention: a new era. Cardiovasc Revasc Med. 2018, 19:35-40. doi: 10.1016/j.carrev.2018.03.020

18. Valsecchi O, Vassileva A, Cereda AF, et al.: Early clinical experience with right and left distal transradial access in the anatomical snuffbox in 52 consecutive patients. J Invasive Cardiol. 2018, 30:218-223.

19. Soydan E, Akın M: Coronary angiography using the left distal radial approach: an alternative site to conventional radial coronary angiography. Anatol J Cardiol. 2018, 19:243-248.

10.14744/AnatolJCardiol.2018.59932

20. Coughlan JJ, Zebrauskaite A, Arnous S, Kiernan TJ: Left distal trans-radial access facilitates earlier discharge post-coronary angiography. J Interv Cardiol. 2018, 31:964-968. 10.1111/joic.12559

21. Kim Y, Ahn Y, Kim I, et al.: Feasibility of coronary angiography and percutaneous coronary intervention via left snuffbox approach. Korean Circ J. 2018, 48:1120-1130. doi: 10.4070/kcj.2018.0181

22. Koutouzis M, Kontopodis E, Tassopoulos A, et al.: Distal versus traditional radial approach for coronary angiography. Cardiovasc Revasc Med. 2019, 20:678-680. doi: 10.1016/j.carrev.2018.09.018

23. Ziakas A, Koutouzis M, Didagelos M, et al.: Right arm distal transradial (snuffbox) access for coronary catheterization: initial experience. Hellenic J Cardiol. 2018, Epub ahead of print. doi:10.1016/j.hjc.2018.10.008

24. Wretowski D, Krakowian M, Łabyk A, Pruszczyk P, Roik M: Very distal transradial approach (VITRO) for coronary interventions. Postepy Kardiol Interwencyjnej. 2019, 15:42-45. doi: 10.5114/aic.2019.83771

25. Aoi S, Htun WW, Freeo S, et al.: Distal transradial artery access in the anatomical snuffbox for coronary angiography as an alternative access site for faster hemostasis. Catheter Cardiovasc Interv. 2019, 94:651657. 10.1002/ccd.28155

26. Maitra S, Ray BR, Bhattacharjee S, Baidya DK, Dhua D, Batra RK: Distal radial arterial cannulation in adult patients: a retrospective cohort study. Saudi J Anaesth. 2019, 13:60-62. 10.4103/sja.SJA_700_18

27. Gasparini GL, Garbo R, Gagnor A, Oreglia J, Mazzarotto P: First prospective multicentre experience with left distal transradial approach for coronary chronic total occlusion interventions using a $7 \mathrm{Fr}$ glidesheath slender. EuroIntervention. 2019, 15:126-128. 10.4244/EIJ-D-18-00648

28. Mizuguchi Y, Izumikawa T, Hashimoto S, et al.: Efficacy and safety of the distal transradial approach in coronary angiography and percutaneous coronary intervention: a Japanese multicenter experience. Cardiovasc Interv Ther. 2019, 24:1-6. 10.1007/s12928-019-00590-0

29. Lee JW, Park SW, Son JW, Ahn SG, Lee SH: Real-world experience of the left distal transradial approach for coronary angiography and percutaneous coronary intervention: a prospective observational study (LeDRA). EuroIntervention. 2018, 14:995-1003. 10.4244/EIJ-D-18-00635

30. Aqel R, Alzughayyar T, Misk R: Radial: time to go distal. Cardiol Cardiovasc Med. 2019, 3:432-437. 10.26502/fccm.92920093

31. Davies RE, Gilchrist IC: Back hand approach to radial access: the snuff box approach . Cardiovasc Revasc Med. 2018, 19:324-326. 10.1016/j.carrev.2017.08.014

32. Alkhawam H, Windish S, Abo-Salem E: Distal radial artery access among cases with radial artery occlusion for primary percutaneous intervention. Future Cardiol. 2019, 15:169-173. 10.2217/fca-2018-0057

33. Pua U, Sim JZT, Quek LHH, Kwan J, Lim GHT, Huang IKH: Feasibility study of "snuffbox" radial access for visceral interventions. J Vasc Interv Radiol. 2018, 29:1276-1280. 10.1016/j.jvir.2018.05.002

34. Brunet MC, Chen SH, Sur S, et al.: Distal transradial access in the anatomical snuffbox for diagnostic cerebral angiography. J Neurointerv Surg. 2019, 11:710-713. 10.1136/neurintsurg-2019-014718

35. Hull J, Workman S, Heath JI: Snuff box radial artery access for arteriovenous fistula intervention . J Vasc Access. 2019, 20:1129729819871434. 10.1177/1129729819871434

36. Letachowicz K, Gołębiowski T, Kusztal M, Letachowicz W, Weyde W, Klinger M: The snuffbox fistula should be preferred over the wrist arteriovenous fistula. J Vasc Surg. 2016, 63:436-440. 10.1016/j.jvs.2015.08.104 